\title{
The Importance of Capital Controls in Vietnam
}

\author{
TAM BANG VU
}

Associate Professor, Doctor of Philosophy, University of Hawaii-Hilo, tamv@hawaii.edu

\section{ERIC IKSOON IM}

Professor, Doctor of Philosophy, University of Hawaii-Hilo, eim@hawaii.edu

\begin{abstract}
This paper provides a simple theoretical framework on the restriction of short-term investments such as stocks, bonds, and other indirect investments while encouraging foreign direct investment (FDI) as a long-term investment. The theoretical results show that a developing country like Vietnam should maintain certain level of capital controls on short-term investments. The paper then provides an empirical study of the five ASEAN countries that are either in the negotiating process or willing to join the Trans-Pacific Economic Partnership with an emphasis on Vietnam. The empirical results show that FDI has positive effect on GDP per capita in these five countries as a group and as individual economies. In contrast, short-term investment has negative effect on GDP per capita in four economies with Singapore as the only exception.
\end{abstract}

Keywords: capital controls, short-term investments, long-term investments, foreign direct investment. 


\section{INTRODUCTION}

During 2008-2012, Vietnam and Malaysia have been negotiating to join the TransPacific Partnership (TPP) together with the other nine countries, including Australia, Brunei, Canada, Chile, Mexico, New Zealand, Peru, Singapore, and the US. Additionally, the Philippines has expressed its willingness to join TPP as a potential fifth ASEAN partner. The recent negotiation session in Hà Nội during April 16-20, 2012 on investments, which contains the capital control restrictions, have caused concerns that the developed countries in TPP might require a developing country like Vietnam to completely eliminate its capital controls. More than one hundred economists worldwide, this writer included, signed a letter asking the developed countries to restrain from the issue. In general, benefits of full capital liberalization are not clear. A look through existing literature reveals many heated debates on this topic.

Edison et al. (2004) review twelve papers, ten of which do not find any evidence that capital liberalization speeds up economic development. Klein (2005) finds that only $25 \%$ of countries with strong-financial institutions receive positive impact of capital liberalization. Hsieh at al. (2008) write a paper on herding behavior among human beings with empirical evidence that shows how dangerous this behavior could be to the financial markets in Asia and Latin America. Vu (2006) analyzes capital control measures in Malaysia during the Asian financial crisis of 1997-98 and draws lessons for Vietnam that stipulate that Vietnam should not relax its capital controls in the near future.

There are two more papers analyzing causes of the 1997-98 financial crisis in Asia and implications for Vietnam. Moreno et al. (1999, p. 41), and Turley (1999, p. 287), ascribe the causes of the crisis to "corruption, crony capitalism, and weak financial systems." Does this imply Vietnam was clean and its financial systems was strong? Moreno et al. and Turley confirm that this is not the case and warn that Vietnam might be dragged into the crisis but do not comment further on another possible cause. Then why did Vietnam in fact escape the sorrowful experience of their neighbors during 1997-98? The answer lies in Krugman (1999), who points out that capital controls protect a country from crises despite its low-quality governance and weak financial systems. The analysis implies that a combination of all three elements-low-quality governance, weak financial systems, and a full relaxation of capital controls - contributes to the $1997-98$ crisis. 
On the other hand, Vietnam has attracted a high volume of inward FDI flows, which are considered the longest mode of investments. Using data from IMF on investments for Vietnam and four crisis-stricken countries in Asia during 1997-98 (Thailand, Malaysia, Indonesia, and South Korea), we calculate and compare growth rates of FDI to the crisis countries with those to Vietnam. The results show that average growth rate of FDI to Vietnam was greater than either of the four crisis countries during 19901997. This implies that a country might not need full capital liberalization to attract long-term foreign investments. Ngoc and Ramstetter (2004) also show that FDI from foreign firms have accounted for large increases in Vietnamese GDP, which was growing steadily during 1990-2003. Thus, a developing country like Vietnam might not need to eliminate capital controls in order to support its growth.

During 2007-2008, there were massive inflows of short-term capital into Vietnam. Many foreign economists believe that this is one of the reasons Vietnam has deeply affected by the new financial crisis of 2007-08. Moreover, Vietnam also has a high percentage of dollarization. This further weakens the domestic currency and exposes the country to financial crisis. Recently, Jeanne at al. (2012) summarize the worsen conditions in the financial markets worldwide and call for capital controls in most countries, especially for developing countries. The question is: which kind of theoretical framework can analyze this phenomenon? The following section attempts to answer this question.

\section{A SIMPLE THEORETICAL FRAMEWORK}

This simple framework is based on the Heckscher-Ohlin (HO) trade model, extended to allow for changes over time in a dynamic setting. The framework assumes two countries that are producing two goods, $\mathrm{X}$ and $\mathrm{Y}$. Country $\mathrm{F}$ is a foreign investing nation, and country $\mathrm{H}$ is a host one. Each country can be large or small. The investing country is a developed one, and the host country is a developing economy, which has not eliminated capital controls. Assume initially that country $\mathrm{H}$ has medium-quality governance and satisfactory financial systems. This assumption will be relaxed later. The initial production possibility curves are labeled $\mathrm{F}_{\mathrm{o}}$ and $\mathrm{H}_{\mathrm{o}}$ for the foreign nation and the host one, respectively. The initial relative prices are $\mathrm{P}_{\mathrm{Fo}}$ and $\mathrm{P}_{\mathrm{Ho}}$ at the equilibrium points $\mathrm{C}_{\mathrm{Fo}}$ and $\mathrm{C}_{\mathrm{Ho}}$ for country $\mathrm{F}$ country $\mathrm{H}$, respectively. Their social indifference curves are $\mathrm{U}_{\mathrm{Fo}}$ and $\mathrm{U}_{\text {Но }}$ (Figure 1). 


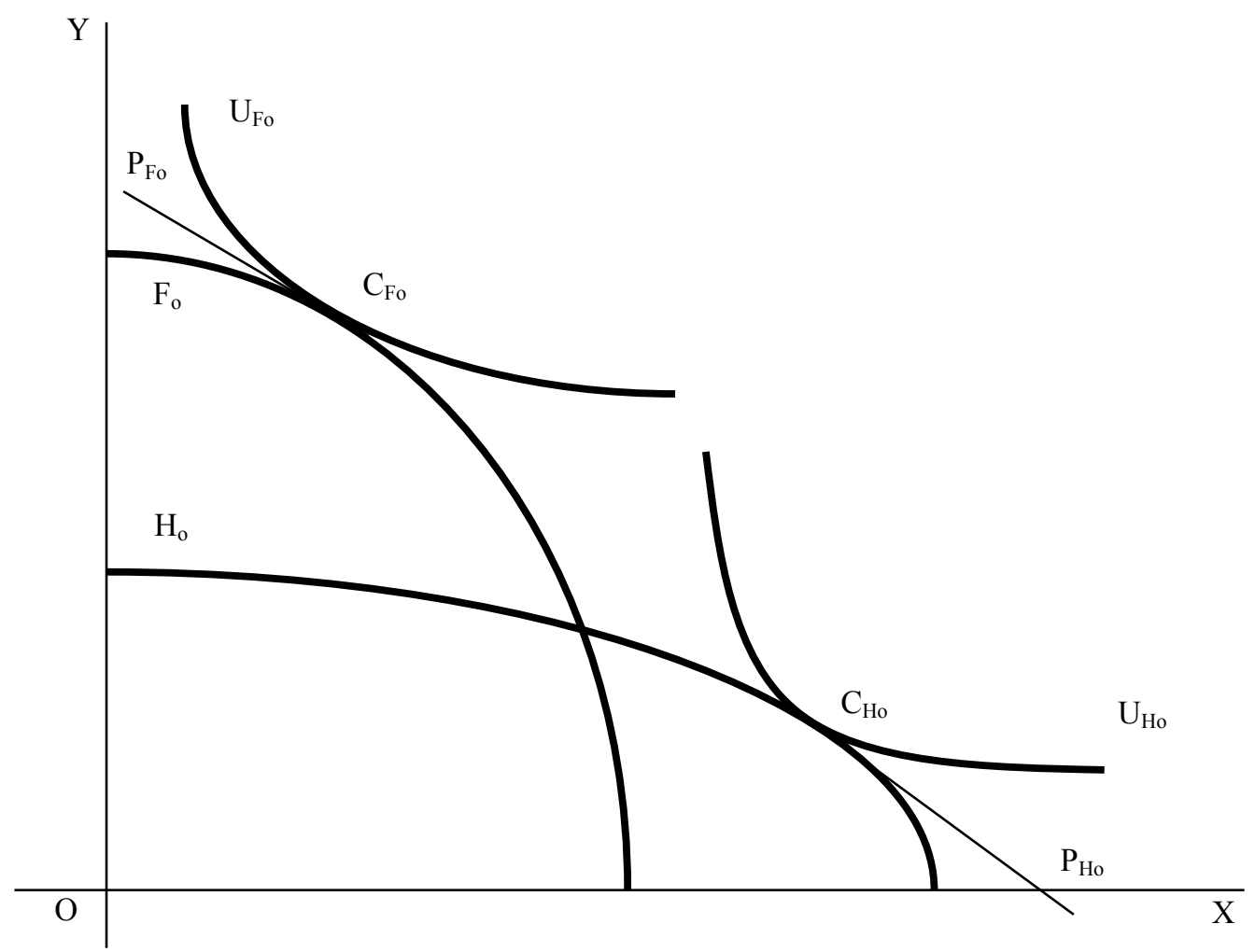

Figure 1: Initial Equilibrium for Each Country

Note: $\mathrm{P}_{\mathrm{Fo}}$ and $\mathrm{P}_{\mathrm{Ho}}$ are initial relative prices for countries $\mathrm{F}$ and $\mathrm{H}$. The equilibriums are at point $\mathrm{C}_{\mathrm{Fo}}$ and $\mathrm{C}_{\mathrm{Ho}}$ where each country's indifference curve is tangent to its production possibility curve $\mathrm{F}_{\mathrm{o}}$ and $\mathrm{H}_{\mathrm{o}}$.

All neo-classical assumptions hold except one: each social indifference curve might change over time due to adjustment costs during the interaction between the two countries. This assumption provides a basis for dynamic analysis once investors of country F enter country H. Note that the Mundell-Fleming model for open economies is not useful for this case due to its static nature.

\section{a. Case One: Country H Imposes Capital Controls}

Suppose that country $\mathrm{H}$ decides to allow massive FDI inflows with only a few short-term investments thanks to its capital control policy. Since country F will only invest if it makes profits and country $\mathrm{H}$ receives extra funds from capital inflows for its domestic investment, their production possibility curves shift out and each country enjoys GDP growth (Figure 2). 
Foreign long-term investors cannot hope to be successful unless they adjusts themselves to country H's culture and law. Since most investors from country F have to adjust themselves, country F's indifference curve will have to bend to become curve $\mathrm{U}_{\mathrm{F} 1}$, which intersects its initial curve $\mathrm{U}_{\mathrm{Fo}}$ at points $A$. In term of utility, country $\mathrm{F}$ would be indifferent between point $\mathrm{C}_{\mathrm{F} 1}$ and point $\mathrm{A}$, which is only as good as point $\mathrm{C}_{\mathrm{Fo}}$. Since country $\mathrm{F}$ still gains from higher GDP growth as shown in Figure 2, it will continue with its investment. By contrast, country $\mathrm{H}$ enjoys a double gain at its new equilibrium point $\mathrm{C}_{\mathrm{H} 1}$ : A higher GDP growth and a higher level of utility shown as curve $\mathrm{U}_{\mathrm{H} 1}$, which is parallel to $\mathrm{U}_{\mathrm{Ho}}$ (Figure 2).

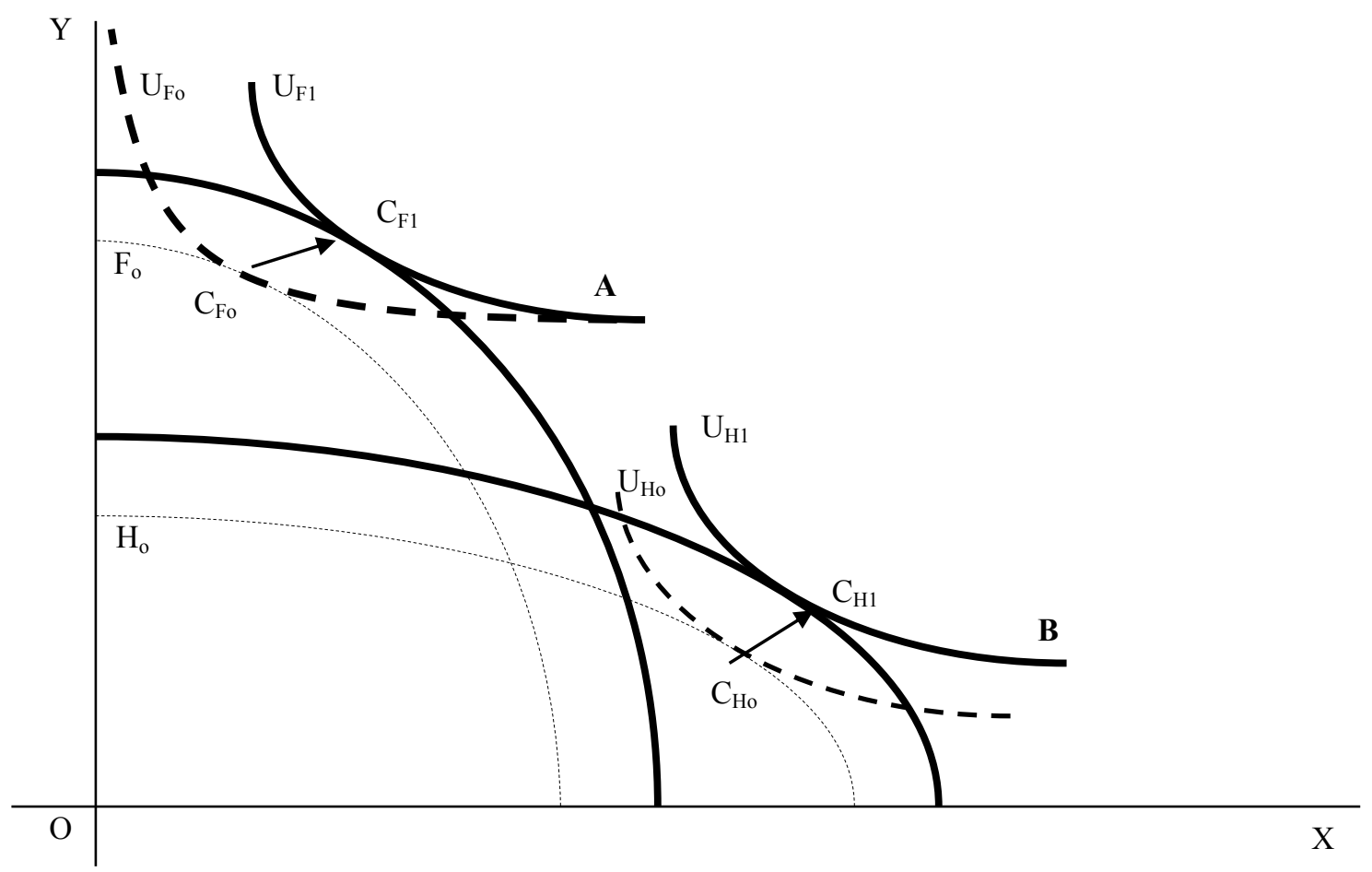

Figure 2: Country H Imposes Capital Controls

Note: The new equilibrium for country $\mathrm{F}$ is at point $\mathrm{C}_{\mathrm{F} 1}$. With capital controls, country $\mathrm{F}^{\prime} \mathrm{S}$ indifference curve $U_{F 1}$ is bended over time and intersects its old curve at point A. Hence, country F's utility does not increase. Country H's indifference curve $\mathrm{U}_{\mathrm{H} 1}$ is parallel to its old curve, and country H's utility level increases. 


\section{b. Case Two: Country H Eliminates All Capital Controls - Adjustments Do Not Affect Production Process}

The process will reverse itself for utility level if country $\mathrm{H}$ eliminates all capital controls. Without any control on financial market, massive short-term and longterm investors are coming in, who will exercise strong influences on country $\mathrm{H}$. The fully open economy will have to adjust itself to the foreign law and culture. Thus, country H's indifference curve will have to bend and so will intersect its old curve. If the adjustments do not affect production process, their production possibility curves shift out, and each country still enjoys economic growth. However, country H's utility level remains the same at point $\mathrm{C}_{\mathrm{H} 1}$, which is only as good as point $\mathrm{B}$, and point $\mathrm{B}$ is only as good as point $\mathrm{C}_{\mathrm{Ho}}$. In the meantime, country $\mathrm{F}$ now enjoys a double gain at its equilibrium point $\mathrm{C}_{\mathrm{F} 1}$ (Figure 3): a higher GDP growth and a higher level of utility with its parallel indifference curves.

This explains Stiglitz's (2002) argument that rich countries used to impose capital controls during their developing periods. Now when they are strong enough to weather all volatility, they are calling for full capital liberalization in all countries for their own benefits instead of benefits of the developing ones. 


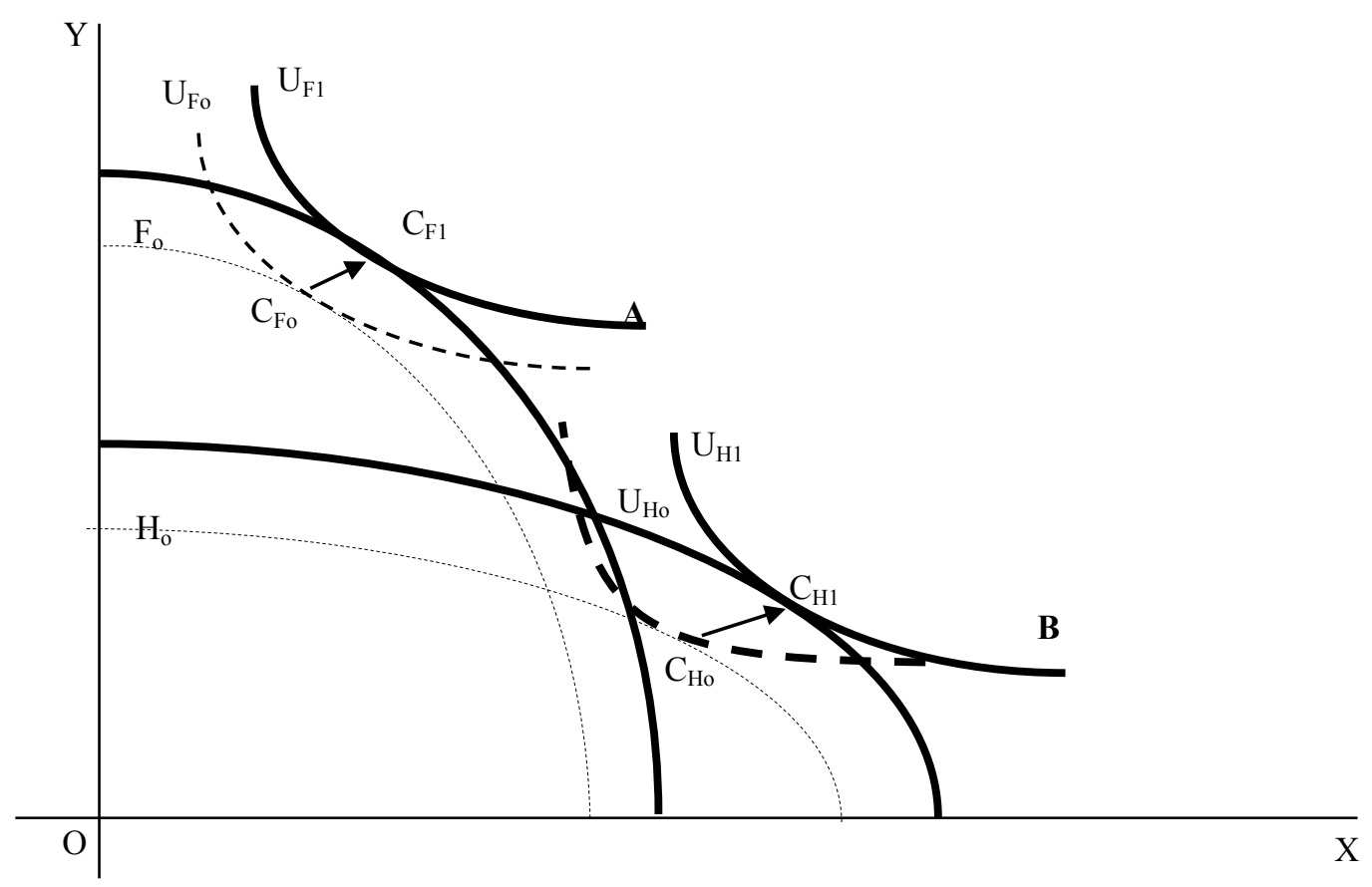

Figure 3: Country H Eliminates All Capital Controls

Note: The new equilibrium for country $\mathrm{H}$ is at point $\mathrm{C}_{\mathrm{H} 1}$. With both massive short-term and longterm investments, country $\mathrm{H}^{\prime} \mathrm{s}$ indifference curve $\mathrm{U}_{\mathrm{H} 1}$ is bended over time and intersects its old curve at point B. Hence, country H's utility does not increase. Country F's indifference curve $U_{\mathrm{F} 1}$ is parallel to its old curve, so country F's utility increases.

\section{c. Case Three: The Adjustments Also Affect Production Process}

Assume from now on that country $\mathrm{H}$ is not allowed to impose capital controls. If the adjustment is also costly in term of money and efforts spent to obtain foreign information, then production possibility curve of country $\mathrm{H}$ might not shift out. Hence, country $\mathrm{H}$ gains nothing in eliminating all capital controls while country $\mathrm{F}$ continues to have a double gain (Figure 4). In this case, the growth and welfare effects for country $\mathrm{H}$ are insignificant and those for country $\mathrm{F}$ are positive. These results fit empirical evidence in the literature. 


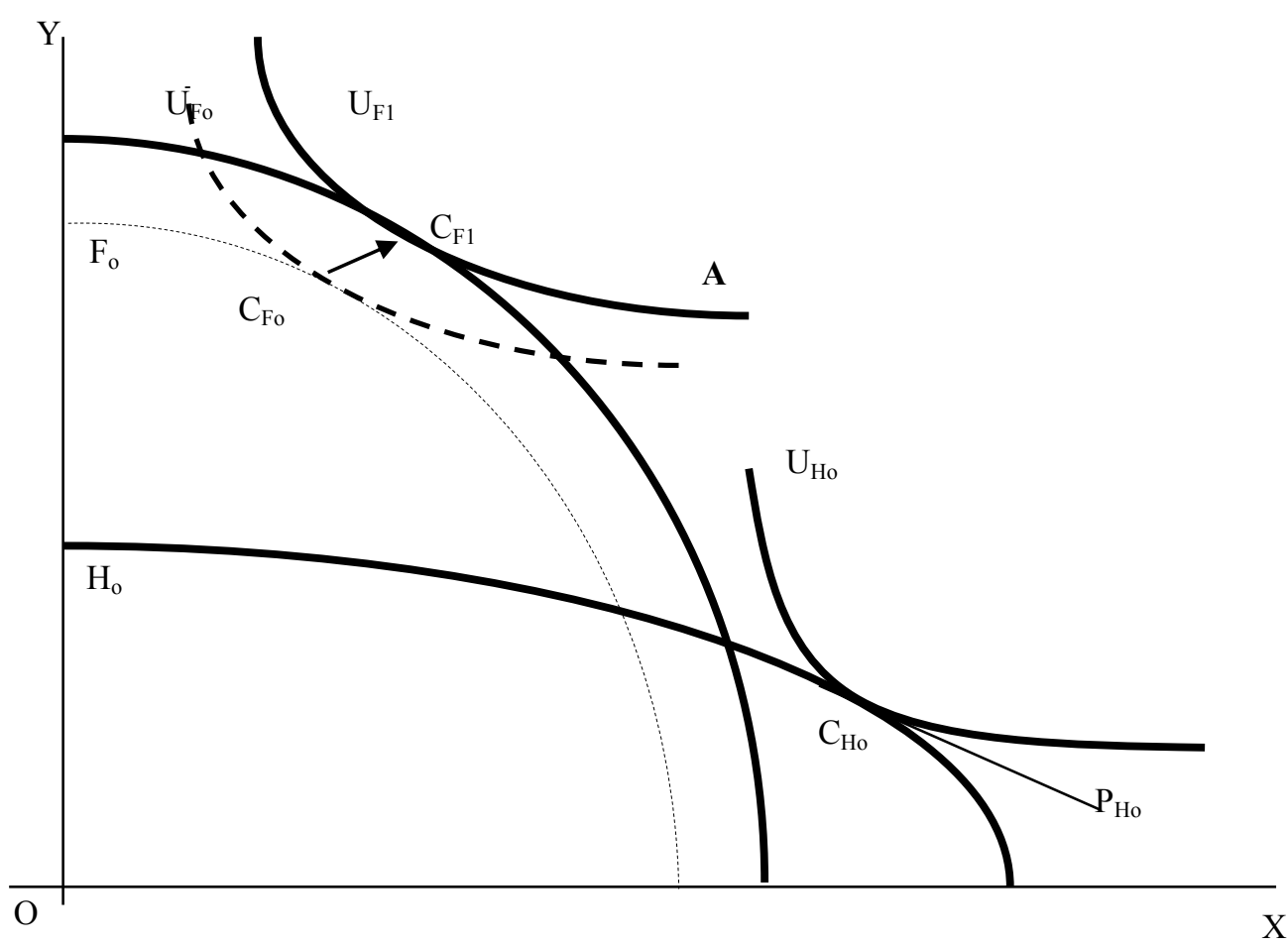

Figure 4: Adjustment Also Affects Production Process

Note: If the adjustments are very costly, country H's production possibility might not shift out due to waste money and efforts spent to obtain information from the foreigners. In this case, country $\mathrm{H}$ gains nothing from eliminating capital controls.

\section{d. Case Four: There Is Low-Quality Governance and Weak Financial System}

If country $\mathrm{H}$ also has low-quality governance, then instable macroeconomic conditions and corruption will further decrease the effect of foreign investments and cannot offset the cost-of-adjustment loss. Hence, the effect of full capital liberalization might become negative, which fits empirical evidence as well. If it also has weak financial systems, then short-term investors' speculations against domestic currency can make country H's indifference curve become non-convex due to hidden information (Figure 5).

In this case, there is a market failure due to asymmetric information, and country $\mathrm{H}$ 's production equilibrium is at point $\mathrm{Q}_{\mathrm{Ho}}$, but its consumption is at point $\mathrm{C}_{\mathrm{H} 1}$. If 
country $\mathrm{H}$ also fails to defend itself against a speculative attack, then the market crashes, leading to a financial crisis, or a currency crisis, or both. As a result, country $\mathrm{H}$ is at big loss, which also fits theoretical and empirical results in the literature.

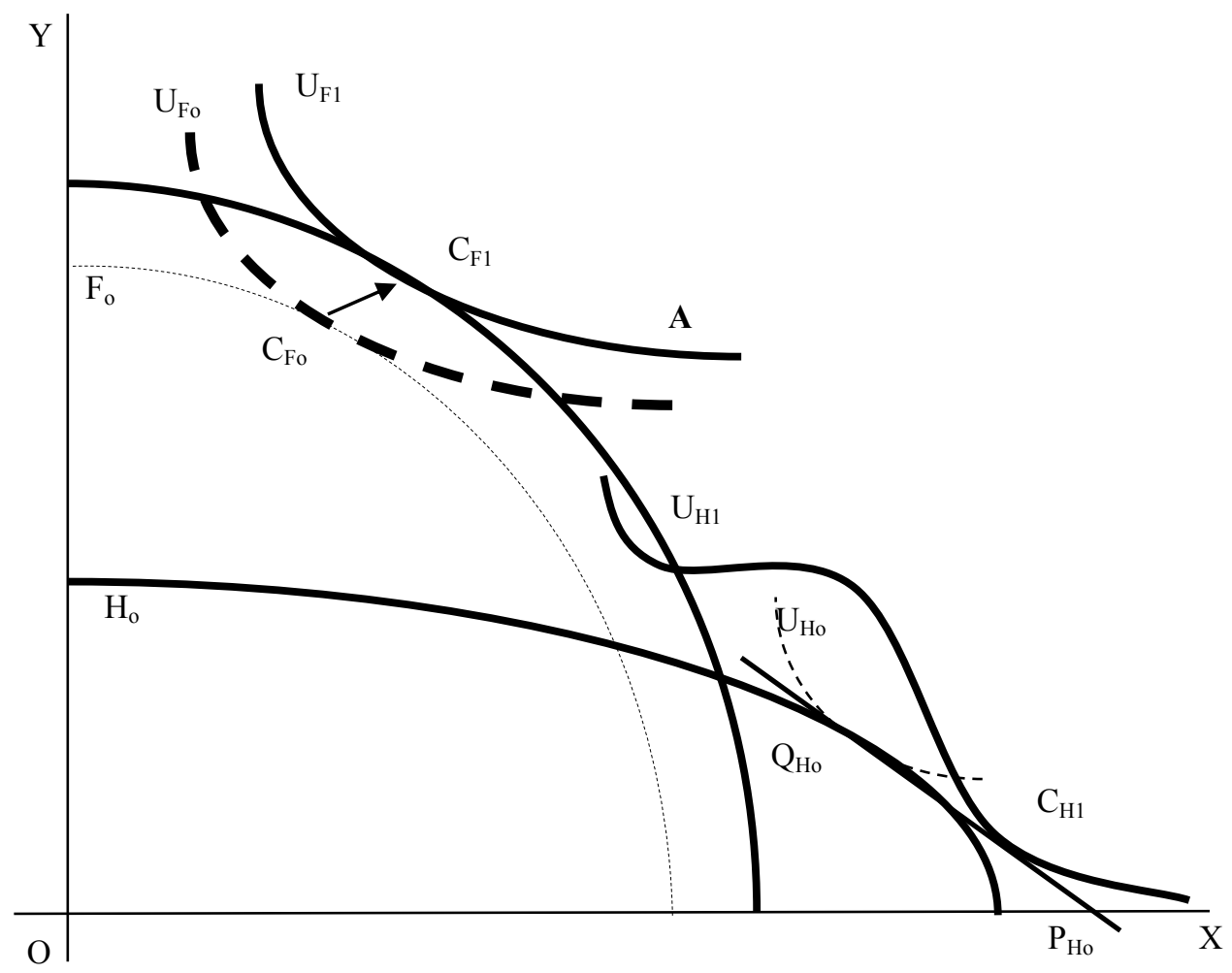

Figure 5: Market Failure due to Asymmetric Information

Note: With weak financial systems and low-quality governance, country H's indifference curve, $\mathrm{U}_{\mathrm{H} 1}$, might become non-convex due to too much hidden information. Its production is at point $\mathrm{Q}_{\mathrm{Ho}}$, where its production function is tangent to the price line $\mathrm{P}_{\mathrm{Ho}}$, but its indifference curve is tangent to $\mathrm{P}_{\mathrm{Ho}}$ at point $\mathrm{C}_{\mathrm{H} 1}$. Thus, the equilibrium breaks down and country $\mathrm{H}$ might suffer a loss. This also occurs if its production function becomes non-convex. 


\section{EMPIRICAL EVIDENCE}

We carry out data analysis on the effect of long-term FDI versus short-term investments (stocks, bonds, and other indirect investments) on economic development using the following equation:

$$
y_{i t}=\gamma_{0}+\gamma_{1} F D I_{i, t}+S H O R T_{i, t}+\sum_{p=1}^{q} \phi_{p} C_{p, t}+r_{i}+t_{t}+\varphi_{i, t}
$$

where $\mathrm{y}$ is the real GDP per capita, FDI and SHORT stand for net foreign direct investments and net short-term investments per person, respectively. Subscripts $\mathrm{i}$ and $\mathrm{t}$ are for countries and time with their respective disturbances. Vector " $\mathrm{C}$ " consists of control variables such as physical and human capital, exports, and interest rates, etc.

We collect data for five ASEAN countries, including four countries that are negotiating to join the TPP-Brunei, Malaysia, Singapore, and Vietnam - in addition to the Philippines that is willing to join. Data on several variables for Vietnam are only available during 1996-2011, so this is the time period for this paper. Data on FDI, short-term investments, real GDP, population, exports, real exchange rate, real interest rate, standing of gross capital formation as a proxy for physical capital, and literacy rate as a proxy for human capital, for the five countries are from Asian Development Bank (ADB), the United State Department of Agriculture (USDA) Economic Research Service, World Bank, and International Monetary Fund (IMF) web sites.

Preliminary tests show that a possible two-way causality does not exist, neither is any endogenous problem, so three stage least squares or two stage least squares approaches are not needed. The VIF test does not point to any multicollinearity problem, and the RESET Ramsey test shows that there is basically no omitted variable. The Hausman test on the two panel data techniques also reveals that a random effect approach is more appropriate than a fixed effect procedure, so the research is carried out using random effect estimations to increase the efficiency of the estimators.

Table 1 reports the results for the aggregate effect. The sign of each variable is as expected. Specifically FDI has a positive effect on GDP per capita whereas short-term investment has negative effect for the five countries as a group. Both effects are statistically significant. Exports, physical capital, and human capital all have positive and significant effects on GDP per capita. The coefficients of the two monetary variables, real interest rate and real exchange rate, have negative signs and statistically 
significant. These make sense, as lower interest rates and exchange rates increase domestic investment and exports, which affect GDP positively.

Table 1: Aggregate Effect of FDI and Short-Term Investments on GDP per Capita

\begin{tabular}{lccc}
\hline \multicolumn{1}{c}{ Variable } & Coefficients & Standard Error & p-value \\
\hline Exports & $0.3555^{* * *}$ & 0.1470 & 0.016 \\
FDI & $0.2481^{* * *}$ & 0.0914 & 0.007 \\
Exchange Rate & $-0.1286^{* * *}$ & 0.0365 & 0.000 \\
Short-Term Investment & $-0.1097^{* *}$ & 0.0464 & 0.018 \\
Physical Capital & $0.3739^{* * *}$ & 0.0464 & 0.000 \\
Interest Rate & $-0.1972^{* *}$ & 0.0813 & 0.015 \\
Human Capital & $0.7759^{* * *}$ & 0.2042 & 0.000 \\
\hline Sample size: & & 80 & \\
Wald Chi-Squares: & & 675.64 & \\
p-value for Chi-Squares: & & 0.0000 & \\
Overall R-Squares: & & 0.9037 & \\
p-value for autocorrelations: & & 0.4879 & \\
p-value for the for White test: & & 0.4765 & \\
Average VIF for & & 2.658 & \\
multicollinearity & & 0.6376 & \\
p-value for the Hausman test: & & & \\
p-value for RESET Ramsey & & & \\
test: & & & \\
\hline Nor & & & \\
\hline
\end{tabular}

Note: $* *$ and $* * *$ indicate statistical significance at $5 \%$ and $1 \%$ levels, respectively.

To examine the effect of FDI on each country's GDP per capita, we then generate four dummies for Malaysia, the Philippines, Singapore, and Vietnam. Brunei, which enjoys the highest effect, is used as the base group for comparison and contrast. For the effect of short-term investment, Singapore is the only country that enjoys a positive and significant effect and is used as the base group. Table 2 reports the results for these 
benchmark variables (the results for the other variables are similar to those in Table 1 and are available upon requests). Coefficient for each country is added to the base's coefficient and F-test is performed, which show that each sum is statistically significant. Comparing and contrasting the five countries, one can see the effect of FDI on GDP per capita is strongest for Brunei, then Singapore, the Philippines, Vietnam, and Malaysia, in that ranking order.

Concerning short-term investments, the effects on GDP per capita are negative and statistically significant in four of the five countries, except Singapore, with the Philippines suffers the most. The effect of short-term investments in Vietnam is similar to those in the remaining two countries. It is easy to understand that Singapore enjoys a positive effect: it is a developed country with highest government management skills, lowest corruption, and strongest financial system among these five countries, so it is the only country that can harvest the reward of short-term investments.

Table 2: Country-Specific Effect of FDI and Short-Term Investments on GDP per Capita

Results for Benchmark Variables

\begin{tabular}{lccc}
\hline \multicolumn{1}{c}{ Variable } & Coefficient & $\begin{array}{c}\text { Standard } \\
\text { Error }\end{array}$ & p-value \\
\hline FDI & & & \\
Brunei & $0.7549^{* * *}$ & 0.1969 & 0.000 \\
Malaysia & $-0.5562^{* * *}$ & 0.2056 & 0.007 \\
The Philippines & $-0.3669^{* *}$ & 0.1834 & 0.046 \\
Singapore & $-0.1971^{* *}$ & 0.0774 & 0.011 \\
Vietnam & $-0.3720^{* *}$ & 0.1638 & 0.023 \\
\hline Short-term investment & & & \\
Singapore & $0.4473^{* * *}$ & 0.1702 & 0.008 \\
Brunei & $-0.4778^{* * *}$ & 0.1702 & 0.006 \\
Malaysia & $-0.4771^{* * *}$ & 0.1696 & 0.005 \\
The Philippines & $-0.5688^{* *}$ & 0.2085 & 0.042 \\
Vietnam & $-0.4799^{* * *}$ & 0.1703 & 0.007 \\
\hline
\end{tabular}


Sample size:

Wald Chi-Squares:

p-value for Chi-Squares:

Overall R-Squares:

p-value for autocorrelations:

p-value for the for White test:

Average VIF for multicollinearity

p-value for the Hausman test:

p-value for RESET Ramsey test:
80

469.34

0.0000

0.9134

0.5265

0.6102

2.814

0.4398

0.4956

Note: $* *$ and $* * *$ indicate statistical significance at $5 \%$ and $1 \%$ levels, respectively.

\section{IMPLICATIONS AND CONCLUSION}

The benefit of eliminating all capital controls has been a controversial topic since the Asian crisis of 1997-98 and even more so after the global crisis of 2007-08. Theoretically and empirically, the positive impact of full capital liberalization is not clear. An agreement among the researchers is that a country needs mature banking and financial institutions in addition to high-quality governance to benefit from massive financial flows.

The results imply that the process of removing capital controls must be placed in each country's historical and local context instead of going hand-in-hand with trade negotiations in TPP. Capital markets are extremely volatile, so any policy concerning financial openness should be carried out with cautions to avoid the painful experience of the past Asian crisis and the recent global crisis. If capital markets were fully opened, debts to the foreign banks would increase and cause anxiety among investors in monetary and financial markets. This makes domestic banks and financial institutions more vulnerable to bank runs.

In the case of Vietnam, bank runs might quickly cause insolvency and crises since the private banks are very weak and dollarization is high, so bank reserves are very low. Once a crisis occurred, the state-own banks cannot rescue the private ones, as the state ones have their own problems aforementioned in the introduction. This might lead to a total economic recession. The Vietnamese government should make careful judgment and slowly open the financial market to short-term investment through many 
phases, in the meantime monitoring closely the activities and management of the private banks. Efforts should also be made to reduce dollarization level by reducing inflation and budget deficit in order to increase Vietnamese confidence in the Vietnamese Dong. The prohibition of the people in keeping US dollars is not a very effective method to control the financial market and can only use as the last resort when all other methods fail.

Due the small sample size and the characteristics of the random effect method, the magnitude of the estimated coefficients should be interpreted with caution. Additionally, this paper focuses on the effects of FDI and short-term investments on GDP per capita. Several attractive topics, such as finding out the effects of these variables on consumer utility as presented by per capita consumption or the effect of short-term investments on labor productivity, will be left for future economists

\section{References}

Aizenman, J. \& I. Noy (2006), "Endogenous Financial and Trade Openness", Review of Development Economics, Vol. 13, No. 2, pp. 175-189

Edison, H., M. Klein, 1. Ricci \& S. Torsten (2004), Capital Account Liberalization and Economic Performance: Survey and Synthesis, IMF Staff Papers, Vol. 51, No. 2, pp. 220-256.

Hsieh M. F., Yaung Y-T, and T.B Vu (2008), "Do Herding Behavior Influence Capital Inflows? Evidence from Asia and Latin America", International Journal of Business and Finance Research, Vol. 2, No. 2, 19-34.

Jeanne, O., A. Subramanian \& J. Williamson (2012) Who Needs to Open the Capital Account?, ISBN Working paper, 978-0-88132-511-9.

Klein, M. (2005), Capital Account Liberalization, Institutional Quality, and Economic Growth: Theory and Evidence, Fletcher School, Tufts University, and NBER, pp. 1-35.

Krugman, P. (1999), The Return of Depression Economics, Norton \& Company, New York, NY.

Moreno, R, G. Pasadilla \& R. Eli (1999), “Asia’s Financial Crisis: Lessons and Implications for Vietnam" in Leung, S. (ed.), Vietnam and the East Asian Crisis, Northampton Publisher (Boston, MA) pp.31-54.

Ngoc, P.M. \& e.d. Ramstetter (2004), “Foreign Multinationals and Local Firms in Vietnam's Economic Transition", Asian Economic Journal, Vol. 18, No. 4, pp. 371-404.

Tanzi, V. (2000), Policies, Institutions and the Dark Side of Economics, Edward Elgar (Boston, MA). 
Turley, W. (1999), "Vietnam" in Jackson, K. (ed.), Asian Contagion, Westview Press (Boulder, CO) pp. 269-296.

Vu, T. Bang, (2006) "Capital Controls in Malaysia and Lessons for Vietnam," East-West Center Working Paper Series. 